\title{
Discussions on the Teaching of Piano Accompaniment in Normal University
}

\author{
Xin Li \\ School of Music and Dance, Yunnan Normal University, Kunming City, Yunnan Province, 650500, China
}

Keywords: musicology; teachers' major; piano accompaniment; the present situation of teaching

\begin{abstract}
Piano playing is an important form of performance. It mainly consists of 3 performances, including piano solo, duet and accompaniment. The piano accompaniment is also known as the piano art instruction, and it is a widely-used form of music art performance. After years of practice, piano accompaniment has gradually formed its unique artistic charm and plays a leading role in the piano solo, playing an irreplaceable role in music performance. Piano accompaniment, because of its unique means of expression and artistic form, and its wide coverage and strong practicality, requires players to have many aspects of music knowledge and high playing skills. Therefore, it is necessary to explore the current situation of piano accompaniment teaching and the cultivation of students' piano accompaniment ability, so as to make piano graduates more suitable for the needs of social development.
\end{abstract}

\section{Introduction}

Piano accompaniment is an important practical discipline based on piano playing in the curriculum of music education in normal universities. It is an independent discipline with its own rules. Along with the reform of piano teaching deeply, for Piano Teaching in what as the center has gradually formed a consensus in varying degrees; whether it is from the point of view of social demand, or from the training goal of high professional music education, piano teaching should be accompanied with the piano as the center [1-2]. Although the piano accompaniment plays an important role in cultivating students' comprehensive quality and practical ability to work, but because of the level of teaching materials for the accompaniment of a student's comprehensive quality is uneven, with some degree of importance for colleges in this class is not enough, resulting in the progress of teaching this course not [3]. Therefore, it is very necessary to discuss how to improve the teaching quality of the piano accompaniment course in the higher music teacher education.

\section{The connotation and characteristics of piano accompaniment}

\subsection{The connotation of piano accompaniment}

Piano accompaniment is an independent, special and special music performing art. It is a comprehensive art for various art services such as instrumental music, dance and vocal music. Piano accompaniment not only serves art as background, but also serves as an indispensable part of the whole stage art structure. It plays an important role in the connotation and emotion expression of music works. Piano accompaniment can serve a variety of artistic forms, such as vocal piano accompaniment, instrumental piano accompaniment, and dance piano accompaniment, and play an important role. Piano accompaniment is a powerful and comprehensive form of music art performance. Piano accompaniment is also divided into two kinds of piano improvisational accompaniment and Piano positive spectrum accompaniment. Piano impromptu accompaniment refers to the improviser's improvisation and accompaniment for the music, on the premise of the melody of the music [4]. Therefore, the improvisational accompaniment requires not only the skillful playing skills of the piano, but also the strong comprehensive quality of the music. The piano positive spectrum accompaniment refers to the player's direct playing of the piano accompaniment that has been formed and completed with the performers. The piano positive spectrum accompaniment requires a certain degree of accuracy and normalization. 


\subsection{The characteristics of piano accompaniment}

Piano improvisation accompaniment is a professional art form that combines player's piano playing ability and comprehensive theory knowledge of piano music, and its characteristics are mainly reflected in the two characters of improvisation. The player should not only have flexible skills, quick thinking, need to master the accompaniment, vocal arrangements and other musical theory, playing skills but also to have the combination of ear, brain, eye, hand etc.. Listen to play accompaniment, harmony through the ear, using the brain thinking, combined with the form of stage performance or require improvisation, then hand eye, sends out the corresponding instruction, the piano accompaniment improvisation spectrum played out, and performing art harmony in one [5]. Because the piano positive music accompaniment is that the orchestra fully considers the stage performance form or the request to make up carefully, therefore, the player has known the accompaniment melody, only needs to mark according to the spectrum surface, and through certain practice, can play the accompaniment skillfully.

\subsection{Analysis of the current situation of investigation}

In order to understand the status quo of piano accompaniment course in higher education, collecting related to the high Shigang with curriculum views, opinions and suggestions, this paper designs a questionnaire (see Appendix), and published in a number of forums, BBS music through the internet. From the feedback results collected, we have mastered the basic outline of the current piano accompaniment curriculum in normal universities, and got some useful inspiration. The following is a detailed analysis of the results of the questionnaire [6]. Only less than $4 \%$ of the interest in steel accompanied classes showed no interest, and a sense of comparison or very interest reached $65 \%$. To exclude some of the factors that are not submitting questionnaires to those who are not interested in it, it is still possible to show that the piano accompaniment course has a certain position in the heart of the people. However, compared with the piano playing course, only 23\% of the people thought that steel accompanied class is more important. Only 15 people think it is very important, less than $12 \%$, as shown in Figure 1.
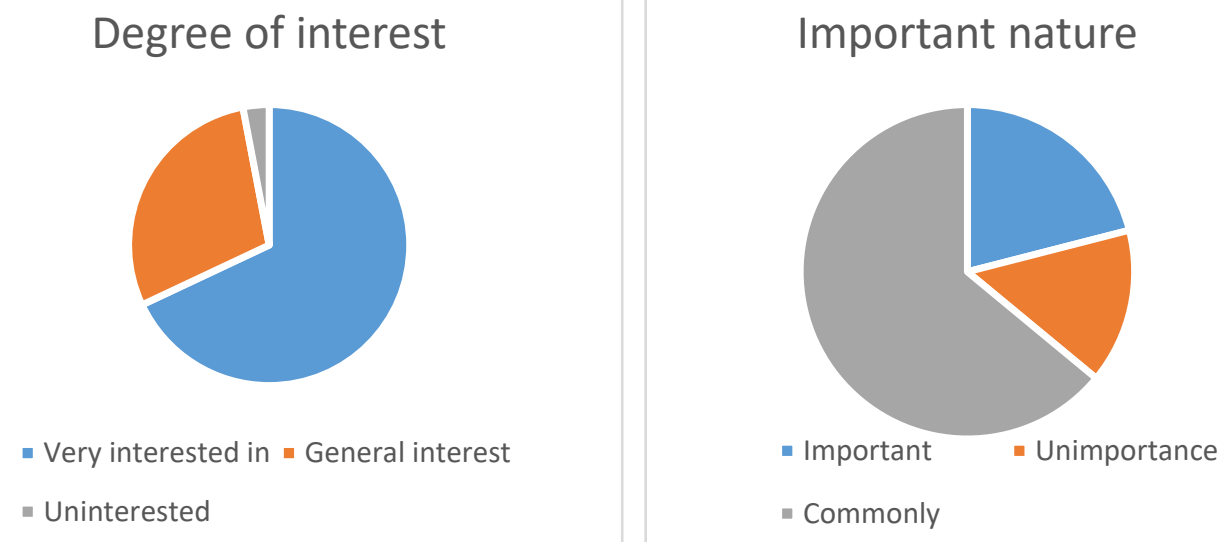

Figure. 1 Distribution of interest and importance

The following issues are mainly aimed at the opening of the accompaniment course of the teacher's normal university. First of all, the problems in the curriculum setting is reasonable, up to $65 \%$ of the people think it is not reasonable, only $1 / 5$ people think reasonable; and for the steel with class problems, we think that the main "lack of connection between each subject, the lack of comprehensive ability training" (47\%) and "teach the old material, the lack of practical" (43\%), in addition to nearly $28 \%$ of the people think "class time is not enough, only 6 of people think that there is no problem, as shown in Figure 2.

In the course of course opening, more than half of the universities set up a year of steel companion, and $1 / 4$ is opened for half a year. It can be seen that from the opening time, most universities can attach importance to the steel companion course. However, the results from the students' attention and learning effect are not satisfactory, which may indicate that there are some 
inherent problems in the setting of steel accompanying courses, as shown in Figure 2.

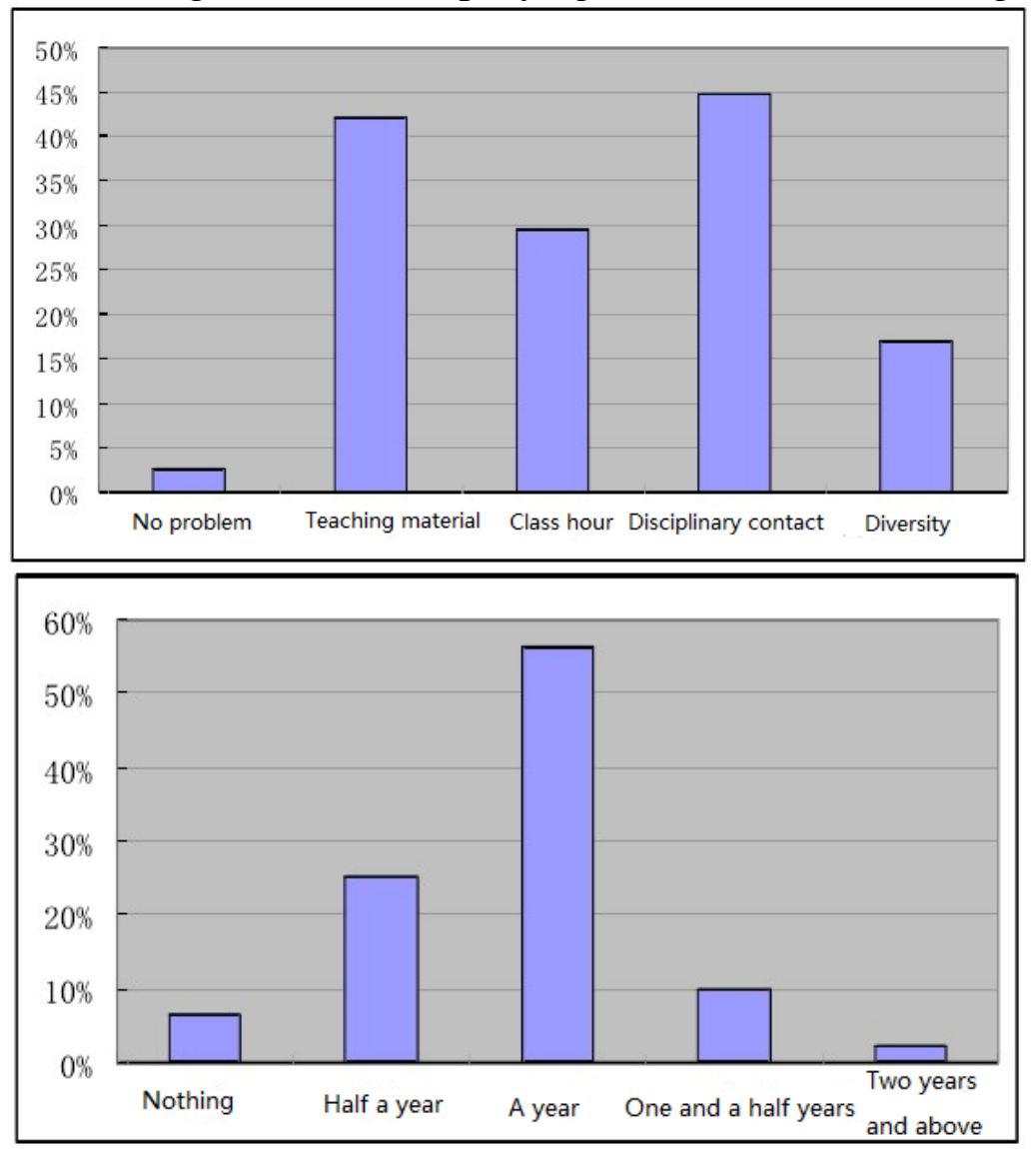

Figure. 2 Degree of rationality and time distribution

\section{The main points of piano accompaniment teaching in normal school}

\subsection{Pay attention to the differences of students and carry out classified teaching}

In normal piano teaching, we should thoroughly study the student's reality, including the student's basic level) after school study, the growth environment, etc., starting from all the details, we will comprehensively analyze the differences between students, and draw up a more detailed classified teaching plan. The survey found that many students have not been in contact with the piano in their previous career and have not heard of the piano music, and almost know nothing about them. Some students have excellent family conditions. Parents also attach great importance to children's interest cultivation. Therefore, such students usually have reached a certain level of piano playing level [7].

\subsection{Cultivate patience and perseverance in the course of teaching}

As mentioned above, there is a huge difference between students' level of playing the piano, for those of poor level of students, teachers should pay more attention and patience, not showing boredom, otherwise, the students will suffer the negative mood, reduce the learning efficiency and quality [8]. In the process of piano learning, students must cultivate their perseverance and realize that learning piano is not a matter of a single day. We must persevere in practice. In this process, teachers should also give encouragement and guidance in time.

\subsection{Establish the basic goal of piano accompaniment teaching}

The teaching of piano accompaniment in normal schools needs to formulate more reasonable and specific teaching objectives according to their actual situations and students' learning needs, so as to ensure that all teaching tasks are carried out in an orderly way around this goal [9]. 


\section{Teaching strategy of piano accompaniment in normal school}

\subsection{Fully stimulate the learning autonomy of secondary normal music students}

Students' autonomous learning is more efficient than passive learning, and the knowledge gained is more systematic and comprehensive. This is also the efforts of all teachers to improve students' autonomy. The main reasons for motivate students' subjective initiative. The teaching of piano accompaniment in secondary normal schools should fully stimulate students' learning autonomy. Before that, teachers should first enable students to master the methods of autonomous learning and have the ability of autonomous learning [10].

\subsection{Improve the efficiency of piano teaching by means of information technology}

Today's era is a highly informative era, education information is also in the full promotion. In the process of promoting information teaching, teachers should actively transform teaching methods, introduce multimedia teaching technology into piano teaching, enrich teaching contents and enhance interest in teaching [11-12]. The multimedia teaching technology can adjust the situation of information asymmetry in the traditional teaching and promote the education fairness. Normal piano accompaniment teaching can also make use of specific teaching software for simulation demonstration, create a real learning situation for students, and get a good learning experience.

\subsection{Guide students to appreciate music, music training}

Throughout the history of the development of the ancient and modern music, there are too many master musicians. Their work through time and space has become an eternal classic that has been remembered by the world. Normal music teachers should guide the students often appreciate these songs, feel the charm of music master of music.

\section{Conclusions}

In summary, piano accompaniment plays an irreplaceable role in music performance because of its unique means of expression and artistic form, and plays an equally important role as piano solo. However, in fact, many college music pedagogical majors do not attach importance to piano accompaniment teaching, ignoring the important role of piano accompaniment learning in the development of music art. This paper first introduces the connotation and characteristics, reflect the important role of the piano accompaniment of piano accompaniment; and then analyzes the status quo of the piano accompaniment teaching; finally from the cultivation of students' piano playing ability, coordination ability, performance ability three aspects, put forward specific measures to cultivate students' ability of piano accompaniment. It is hoped that this study can arouse more attention to piano accompaniment teaching, promote the further development of piano accompaniment teaching, and provide some references for improving the piano accompaniment ability of students.

\section{References}

[1] Nakada K. The Problems of the Piano accompaniment method at University with Teacher Training Courses (I) [J]. 2011, 60:65-71.

[2] Luo H Y. On Problems and Countermeasures in College Piano Accompaniment Teaching [J]. Journal of Bijie University, 2010.

[3] Bao M W, University S. The Reflection on the Teaching of Impromptu Piano Accompaniment [J]. Journal of Jining Normal University, 2015.

[4] He Q, Jiang C. The Application of Piano Accompaniment Music to Dance Teaching_—Taking "The Basic Training of Chinese Classical Dance" for example [J]. Journal of Guilin Normal College, 2016. 
[5] Yan D, Campus C. Research on the teaching innovation of dance piano accompaniment in art colleges [J]. Journal of Jiamusi Vocational Institute, 2017.

[6] Cao W X. Piano accompaniment in the teaching of folk dance [J]. Journal of Jiamusi Vocational Institute, 2016.

[7] Zhang Z. The Function of Piano Accompaniment in Chorus Teaching[C]// International Conference on Contemporary Education, Social Sciences and Humanities. 2016.

[8] Xue H P, Department T M, University Q N. Teachers Quality in the Impromptu Piano Accompaniment Course [J]. Journal of Qinghai Normal University, 2013.

[9] Bao M W, University S. The Reflection on the Teaching of Impromptu Piano Accompaniment [J]. Journal of Jining Normal University, 2015.

[10] He Q, Jiang C. The Application of Piano Accompaniment Music to Dance Teaching_-Taking “The Basic Training of Chinese Classical Dance” for example [J]. Journal of Guilin Normal College, 2016.

[11] Zhang N, Music S O, University L N. German and Austrian Art Song Piano Accompaniment to Enhance the Role of the Piano Solo Ability of Exploration [J]. Journal of Zhanjiang Normal University, 2014.

[12] Nakada K. The Problems of the Piano accompaniment method at University with Teacher Training Courses (I) [J]. 2011, 60:65-71. 